\title{
Analysis on the Expression of Artistic Aesthetic Value in Piano Performance
}

\author{
Chen Xinyu \\ Mianyang Normal University, Mianyang, Sichuan, China, 621000 \\ Keywords: piano performance; artistic aesthetics; value display \\ Abstract: The most effective way to show the artistic value of art is to hold piano \\ performances. Piano players must present all the content and features of the music works in \\ front of everyone, combine their own views, apply aesthetic skills reasonably, and \\ complete the second creation of music works. Only in this way can the artistic aesthetic \\ value of piano performance be fully demonstrated.
}

\section{Introduction}

Piano performance is the core element of the musical practice process and the main way to show artistic aesthetics. Compared with artistic aesthetics, piano performance is the second work of art. In the performance stage, it can better release the characteristics of artistic aesthetics, help the audience to deepen the interpretation of music, bring the audience into the realm of music, presents the player's personality and style, and resonates with the audience.

\section{Overview of the Value of Fine Arts in Piano Performance}

Piano performance is the embodiment of art. The aesthetic knowledge and thinking involved are very rich, which can make the audience immersive; use music works to express their feelings and resonate with the audience. The artistic aesthetic value of piano performance mainly involves the following points:

\subsection{Musical aesthetics}

Musical aesthetics refers to the evaluation of the level and principles of appreciation of piano players. The contents involved are: the recognition of the music content, the mastery of the playing style, the presentation and presentation of the musical works, the secondary creation of the works, and the research and discussion of the aesthetic skills. Music aesthetics can guide people to understand and deal with various problems from the perspective of artistic aesthetics, and better display the artistic aesthetic value.

\subsection{Artistic aesthetics}

Art aesthetics can also be called art philosophy. The core idea is to explore the connection between art and aesthetics, to achieve the goal of fusion of art and aesthetics, and to understand the 
rules and connections. For piano performance, the performer should fully combine the aesthetic thought and artistic value to better display the music works and let the audience feel the comfort of the music.

\subsection{Axiological aesthetics}

In terms of axiological aesthetics, aesthetics is the premise, and aesthetics is the main embodiment of value. In the process of practice, aesthetic research is based on human life, constructs rigorous and reasonable aesthetic thoughts and aesthetic souls.

\section{The significance of art value in piano performance}

\subsection{Emotional value}

In the aesthetic value of art, emotion is the basis of its premise. Relative to the aesthetic value, It mainly depends on people's feelings. After deep and deep appreciation of piano performance, scientific application of aesthetic skills and aesthetic thoughts, people's minds and souls are released. This release is far more practical than material. For piano performance, emotional expression and auditory shock are the best methods of aesthetic music. Especially the modern people's emotions are extremely rich, and the understanding and expression of music gradually become more diversified. Relative to the emotional level, the aesthetic value of art in piano performance is relatively free and chic, not bound by space and time, enriching people's spiritual life.

\subsection{Artistic aesthetic value}

Aesthetic problems and artistic problems are important manifestations of the artistic aesthetic value of piano performance, and carry out in-depth analysis and research for it. Any of the outstanding artists will always present their artistic theories and their own unique characteristics. Only by combining art theory and artistic thoughts can they play piano works with great artistic feelings for the audience. Compared with artistic aesthetics, piano performance is the art that best expresses the emotion of content.

\section{The principle of artistic aesthetic value in piano performance}

\subsection{Ontological principle}

From a certain point of view, piano performance is a secondary creation for existing works of art. Performers combine their own ideas with artistic aesthetics to present works, similar to labor art. While presenting music to the audience, the pianist also allows everyone to recognize their artistic talents, add their own thoughts and feelings and artistic aesthetics to the music, and truly show the value of music. The sensitivity of music works is very strong, and each pianist looks at the music differently. In the piano performance, let the audience feel the true, good and beauty of the piano, and present the artistic beauty of the music to the audience.

\subsection{Structural principle}

Standing on the perspective of the aesthetic value of piano performance, the structure of music is relatively obvious. Like some professional musicians, the structure of their works is very clear, and the spirit and essence of music are perfectly displayed. The structural principle is not only expressed in the aesthetic value of art, but the most important thing is to expose people's yearning for the 
music environment. Musical harmony is mainly reflected in the music melody, frequency, intensity and pause. According to the appropriate proportions, the unique structure of the music makes the music played by the piano very attractive. Music integrity is the basis of performance. During the performance of the piano, the performer will add his feelings in the music and closely connect with the feelings of the works, so that the structure of the works can be well displayed, and the harmony and stability of the works can be improved.

\section{The embodiment of artistic aesthetic value in piano performance}

\subsection{Combination of history and time}

In piano performance, music is a combination of history and time, which fully reflects the value of artistic aesthetics in piano performance. Different music presents different styles, because the musical works were influenced by the historical situation during the creation period and the psychological changes of the author at that time, even the piano performers' psychological and epochal reforms will have an impact on the expression of the work. A professional piano performer can interpret music works in all aspects and at multiple levels. For the historical perspective and the trend of the times, it is necessary to restore the works to the highest degree and present the perfect music works to the audience. Because the piano is influenced by many factors in the performance, and the cumbersomeness is obvious, the performer can't run counter to the current era when performing the work, and it must show the historical and contemporary nature of the society, thus attracting more audiences.

\subsection{Unification of innovation and simplicity}

Piano players can promote the development of music to some extent during the performance, improve the innovation and simplicity of music works, and finally combine the two. Piano playing is a second creation of music works. In this process, the piano player has a deeper understanding of the emotions that the music works to express and gives the music a new life and artistic value. Based on this, the player's skills are put forward higher requirements, not only to actively innovate the work, but also to maintain the simplicity of the work. Therefore, the performance of the piano performance artist not only restores the spirit of the music work, but also interprets the content and emotions in the music works, and combines the self-understanding to create the works. On the one hand, the performers must preserve the original music, on the other hand, to show their personality.

\subsection{Combination of rationality and sensibility}

When performing their own works, piano artists often put emotions and cognition into their works, so that the audience can understand and recognize the works deeper and feel the meaning of the works, which help the performer to better complete the second creation of the work. Any pianist's interpretation of music is different, and there are great differences in the creation of works, which makes the pianist's aesthetics of music very different. The reason that people often say is that the performers must do basic skills in advance in the performance process, such as the playing method and the control of the rhythm of the performance, which are determined by the characteristics of the music itself and the structure of the piano.

\subsection{Launching creative practice activities}

For music works, the first task is to create practical activities, to show and create the works of 
performers and pianists, only to build in practice can be called creation. Therefore, all the feelings conveyed to the audience during the performance of the piano are the ideas of the performers and creators. For piano performance, all-round motivating player's emotions, only in this way can show the activity and affection of music. When playing a musical piece, the performer should incorporate the real work and fully present the diversity of the musical work. Nowadays, people's aesthetic skills are gradually improved, and the audience has put forward higher requirements for the innovation of piano performance.

\section{The connection between piano performance and artistic aesthetic value and the realization of foundation}

\subsection{The connection between piano performance and artistic aesthetic value}

A professional piano player should have a high artistic aesthetics and a very strong and solid aesthetic foundation. At the same time, the piano performers should also better interpret the artistic aesthetic value of the art works. The artistic aesthetics is extremely important for the pianist. In order to fully demonstrate the artistic aesthetic value, it is necessary to integrate aesthetic art principles and performance rules in the piano performance stage. For a professional pianist, it is indispensable to have a comprehensive control of performance techniques and aesthetic techniques. For a performer whose performance skills and performance techniques are unqualified, the artistic aesthetics is no longer useful and cannot explain the value of music to the audience. In the same way, the higher skill of any performer, once the aesthetic skills and aesthetic literacy are poor, cannot show the artistic beauty and value of the pianist. Piano performance is the key method to show the value of music. It perfectly presents the personal feelings hidden in the music works. Whether it is a restored work or a re-created work, the artistic aesthetic value can be seen. In a sense, the main purpose of the piano player is to show the aesthetic value and show the audience the delicate and magical art.

\subsection{The Foundation of the Aesthetic Value of Piano Performance Art}

Analyze from the perspective of the performance subject, the performers need to integrate the playing method and the artistic beauty as soon as possible. In art performances, piano performance is the core element, and it can directly innovate the art environment, so that people can truly understand the value brought by art aesthetics. Players should strengthen their training and practice in performing techniques and skills. It is necessary to regard aesthetic ability as the focus of training so that the second creation of musical works can be fully realized.

\section{The quality requirement of performers in piano performance}

\subsection{Sensibility and rationality coexist}

Music is the artistic bridge of people's emotional world communication, which is shown by piano players. In the performance, the sensibility and rationality of the player coexist, allowing the audience to listen better. The melody and style in the music language are the main window for the interpretation of music works, and the music strength, speed and rhythm characteristics must be handled well. If the player's emotional experience is rich, then they will help them to play good works, such as Beethoven's "Storm" and "Moonlight", using the natural scenery to present the classicism of equality, freedom and rational spirit; The soft melodies of "Moonlight" are displayed in the minds of the performers, reminding them of the whiteness and gentleness of the moonlight, 
the comfort of the rhythm and the melody of the lines in the weaker category. In actual performance, the emotional image plays a vital role in it, the depth of the work requires rational thinking and judgment to obtain. That is to say, the performer should have a very good understanding of the work, and also have a good understanding of the historical background and cultural background of the work, as well as the creative thoughts and ideas of the composer. The reason why Beethoven's music history can be praised by the world is that it condenses the spirit of the classicism and does not lose the aesthetic audibility.

\subsection{Psychological state and performing skills}

Playing psychology is an extremely cumbersome process that includes the player's mood, inner hearing, psychological manipulation skills, and the direction of the limbs. A good playing psychology is mainly attributed to the player's psychological state, followed by the player's inner auditory and acoustic communication form, which is the so-called psychological sensing state. Psychological tension is mainly due to the player's dynamic feeling of the actual sound is weak, and there is no mapping relationship with his inner hearing. The soothing mood can better adjust the playing atmosphere, and the actual acoustic sensibility and inner hearing produce the mapping process, thus showing the good or bad of the player's psychological skills.

\section{The way to display the aesthetic value of piano art}

First, the tone. The core method of distinguishing between different instruments is the tone. The main reason for the piano to form such a tone is the vibration of the piano strings. The vibration frequency and the state are different, and the waveforms of the musical note are different, and the sounds are different. At a deeper level, because the piano has different materials, different sounds can be presented. The particularity of the material is the main reason, it is difficult to change based on objective factors. Any piano performer has different playing skills, and the factors played by him also reflect their own subjective thinking. Performers can use subjective ideas to control the tone and convey emotions. In addition, the frequency and power of the performer directly affects the piano sound.

Second, the pitch. The basic form of piano performance is pitch. Each piano piece incorporates different styles of pitch, which are then arranged and combined to form a tone that turns into a moving melody along the rhythm. The song's expressive force will change with the pitch, the treble is louder, the midrange is very subtle and gentle, the bass is relatively raucity and strong. The performer can control the pitch very well to express the sound of the music, giving people a visual impact and making people immersive.

Third, strength and weakness. Piano is a kind of playing instrument. The intensity used in the performance process will have different effects. The vibration frequency directly affects the size of the tone. The standard of artistic aesthetic value in piano performance is the intensity of notes. When the player plays the last note of the clip, the sound of the music is often minimized due to the slower vibration. This feeling is what people often say is like sounds of nature. The piano structure and the strings have undergone a major change. The structural changes have caused some changes in the playing volume of the piano. The player's control of strength and strength can make some changes to the notes to a certain extent, thus playing a beautiful music.

Fourth, the posture is presented. The artistic aesthetic value of piano performance is not only reflected by the sound and characteristics of the piano itself, but also by the action of the performer. According to the survey, when the audience is listening to the track, the first thing that is affected is vision, followed by hearing. Therefore, in order to reflect the aesthetic value of piano art, piano players must have strong playing skills and physical expression skills. Displayed by the posture, not 
only can reveal the author's feelings, but also let the audience understand the emotional changes and draw closer to the player.

Fifth, rhythm and beat. The rhythm is not reflected in the music. In life and in art, there are rhythms of alternating black and white and alternating light and dark. In piano performance, the meaning of rhythm is to complete the performance according to the length of the note, and the effect of different rhythms is different. The cheerful rhythm makes people feel relaxed and the nervous rhythm makes people happy. In general, the rhythm of music is the best form to control the expressive power of music, and is the life of piano music. The beat can show the intensity of the music, often showing a repeating pattern within the specified range. The rhythm and the beat complement each other, and the dynamics of the rhythm are composed of beats. The beats in any piano music are different.

\section{Conclusion}

In short, in order to show the artistic aesthetic value of piano performance, it is necessary to integrate historical and contemporary, to regulate the innovation and simplicity of musical works, and to combine rationality and sensibility to achieve the goal of innovative practice.

\section{Acknowledgment}

Project No. 18SA0089 of "New Research on the Teaching Achievements of Music Aesthetics Theory Practice in Piano Accompaniment Technology" initiated by Sichuan Education Department in 2018

\section{References}

[1] Kang Qin, Du Xuan. On the Embodiment of Artistic Aesthetic Value in Piano Performance [J]. Journal of Hubei University of Science and Technology, 2016, 36(1):149-151.

[2]Wang Xin. Aesthetic Thinking on the Art of Piano Playing [J]. Northern music, 2016,36(19):164-165.

[3] Zhang Xuan. Aesthetic expression and aesthetic stimulation in piano performance art [J]. Musical instrument, 2016(2):44-45.

[4] Wu Fan. Reflections on the Aesthetic Characteristics and Aesthetic Value of Piano Art [J]. Musical instrument, 2017, 37(5):44-45.

[5] Sun Yin, Cai Yunlin. Analysis of the relationship between touch keys and timbre in piano performance [J]. Chinese National Expo, 2016(4):147-148.

[6] Guan Chenchen. The Aesthetic Connotation in the Process of Piano Performance [J]. Sichuan drama, 2017(1):154-157. 